\title{
LOAD BALANCING UNTUK PERBANDINGAN KINERJA VIRTUALISASI SERVER VMWARE DAN XEN SERVER
}

\author{
I Gede Primanata ${ }^{1}$, Nyoman Putra Sastra ${ }^{2}$, Dewa Made Wiharta ${ }^{3}$ \\ Program Studi Teknik Elektro, Fakultas Teknik, Universitas Udayana Denpasar - Bali \\ Email: Igedeprimanata@gmail.com ${ }^{1}$, putra.sastra@unud.ac.id $^{2,} \underline{\text { wiharta@unud.ac.id }}^{2}$
}

\begin{abstract}
ABSTRAK
Penelitian ini bertujuan untuk membandingkan teknologi virtualisasi server VMware dan Xen server yang mensimulasikan perangkat keras ke dalam perangkat lunak. Agar pembagian beban dapat dibuat seimbang pada kedua server virtual, maka pada penelitian ini digunakan HAproxy sebagai Load Balancing yang diimplementasikan pada Web Server Apache dengan demikian kinerja dari sisi penggunaan CPU, memori dan kecepatan akses dari virtualisasi server VMware dan Xen dapat dibandingkan. Dengan membandingkan kedua model ini, diharapkan dapat digunakan sebagai acuan melakukan pemilihan model virtualisasi untuk kebutuhan penggunaan resource bersama pada sebuah atau lebih server fisik. Dari hasil pengujian pada penelitian ini, didapatkan bahwa kinerja VMware lebih baik dari Xen jika ditinjau dari penggunaan CPU. Penggunaan CPU di VMware lebih rendah dibandingkan dengan Xen dengan nilai $1,57 \%$ pada saat menangani satu website dan $1,58 \%$ pada saat menangani dua website. Ditinjau dari sisi penggunaan memori Xen Server lebih hemat dalam penggunaan memori jika dibandingkan dengan VMware, yaitu Xen lebih hemat memori sebesar 29,11\% dan $34,84 \%$ untuk menangani satu dan dua website jika dibandingkan dengan VMware. Sedangkan dari sisi kecepatan akses data pada Xen lebih cepat dibandingkan dengan VMware, yaitu sekitar 42.132 Kbps.

Kata Kunci : Server, Virtualisasi, VMware, Xen
\end{abstract}

\section{ABSTRACT}

This study aims to compare VMware server virtualization technology and Xen server that simulates hardware into the software. In order to share loads can be balanced on both virtual servers, this research used HAproxy as Load Balancing which is implemented on Apache Web Server so performance from CPU usage side, memory and access speed from VMware and Xen server virtualization can be compared. By comparing these two models, it is expected to be used as a reference for selecting virtualization models for shared resource needs on one or more physical servers. From the results of testing in this study, it was found that the performance of VMware is better than Xen when viewed from the CPU usage. CPU usage in VMware is lower than Xen with $1.57 \%$ when handling one website and $1.58 \%$ when handling two websites. In terms of memory usage Xen Server is more efficient in memory usage when compared to VMware, Xen is more efficient memory of $29.11 \%$ and $34.84 \%$ for handling one and two websites when compared to VMware. While in terms of data access speed on Xen faster than VMware, which is about 42,132 Kbps.

Keywords: Server, Virtualization, VMware, Xen

1. PENDAHULUAN

Seiring perkembangan teknologi informasi yang semakin pesat, kebutuhan suatu organisasi juga semakin komplek, terutama dalam menjalankan proses operasionalnya [1]. Sementara itu, kebutuhan infrastruktur teknologi informasi juga semakin meningkat seiring dengan meningkatnya kebutuhan sumber daya teknologi informasi dalam sebuah organisasi [1]. Banyak organisasi telah mengubah media tata kelola, dari secara manual ke system digital. Banyak aplikasi yang dikembangkan untuk selanjutnya digunakan agar organisasi tersebut berjalan dengan baik. Kebutuhan infrasktruktur berupa server fisik, sebagai tempat berjalannya aplikasi semakin banyak. Padahal sering terjadi bahwa setiap aplikasi mempunyai karakteristik yang berbeda, misalnya jumlah pengguna dan trafik 
puncak waktu penggunaan. Sehingga sebenarnya penggunaan resource bersama untuk beberapa aplikasi sangat memungkinkan. Salah satu cara untuk penggunaan resource bersama ini adalah dengan melakukan virtualisasi terhadap server fisik.

Banyak peneliti melakukan penelitian terkait virtualisasi server. Penelitian [2] membahas perbandingan kinerja VMware dan Xen Hypervisior yang mengukur kinerja dari penggunaan CPU, memori, disk, dan sistem waktu dari kedua Hypervisior VMware dan Xen. Metode yang dilakukan adalah menginstal VMware EXSi 6.0 dan Citrix XenServer 6.5 di masing-masing server dengan spesifikasi yang sama kemudian menginstal langsung Guest OS Microsft Windows 2008 R2. Kinerja dari penggunaan CPU, memori, disk, dan sistem waktu dapat dilihat langsung melalui aplikasi yang ada pada Guest OS Microsft Windows 2008 R2.

Sedangkan penelitian [3] adalah mengukur kineja penggunaan CPU, disk, dan waktu respon dari aplikasi secara realtime. Pada setiap jenis virtualisasi server KVM, VMware, dan XenServer terdapat virtual mesin. Pengukuran perbandingan kinerja CPU, memori, dan disk dilakukan pada saat virtual mesin dari masing-masing virtualisasi server menangani aplikasi yang berjalan. Waktu respon diukur dari total waktu yang dibutuhkan oleh server untuk ON dari posisi OFF. Penelitian [4] membahas tentang pengukuran kinerja dari lima pendekatan virtualisasi dengan beban kerja tertentu saat dijalankan menggunakan virtualisasi dan saat virtualisasi tidak digunakan.

Dari ketiga penelitian yang telah dilakukan tersebut, yang disamakan adalah jumlah memori dan CPU di setiap server virtualisasi. Pengaturan beban dilakukan, tetapi tidak ada validitas dari beban yang diatur, sehingga sifatnya hanya asumsi saja. Berdasarkan hal tersebut, maka penekanan pada penelitian ini adalah dengan mengatur dan mengukur beban agar masing-masing server mempunyai beban yang diusahakan sama. Penggunaan metode [5] [6] [7] load balancing HAProxy bertujuan agar server virtualisasi VMware dan Xen mendapatkan beban kerja yang sama. Sehingga tidak hanya jumlah memori dan CPU yang kondisikan sama tetapi beban kerja dari setiap server virtualisasi juga dikondisikan sama menggunakan traffic yang real.

\section{TINJAUAN PUSTAKA}

\subsection{VMware}

VMware merupakan sebuah software virtualisasi server yang bisa menjalankan sistem operasi dalam satu perangkat keras sekaligus menjalankan aplikasi yang di tunjukkan untuk sistem operasi lainnya [8].

\subsection{Xen}

Xen adalah software virtualisasi server

yang mendukung eksekusi beberapa sistem operasi guest dengan isolasi sumber daya dan kinerja optimal (mendekati kinerja sistem bila dijalankan pada perangkat keras yang setara) dan Xen merupakan perangkat lunak bebas yang dirilis berdasarkan lisensi GNU (General Public License) [9].

\subsection{Load Balancing}

Load balancing [6] [7] adalah sebuah proses atau teknologi yang mendistribusikan trafik sebuah situs kepada beberapa server menggunakan sebuah perangkat jaringan.

\section{METODE PENELITIAN}

Penelitian ini dilakukan di Gedung Global Development Learning Network (GDLN) Universitas Udayana Jl. PB Sudirman, Denpasar, Bali, Indonesia dengan data penelitian yang bersumber dari data sheet server fisik VMware (HP ProLiant DL 380 G7) dan server fisik Xen (HP Proliant DL180 Gen 6), buku panduan mengenai virtualisasi server, jurnal, artikel yang berhubungan dengan penerapan virtualisasi server, khususnya VMware dan Xen. Jenis data yang digunakan berupa data primer dan data sekunder.

\subsection{Desain Sistem}

Penelitian ini menggunakan dua jenis virtualisasi server yang berbeda yaitu virtualisasi server VMware [8] dan virtualisasi server Xen yang dikeluarkan oleh CITRIX [9]. Kedua jenis virtualisasi ini terinstall di server (HP ProLiant DL380 G7) sebagai virtual server VMware dan server (HP Proliant DL180 Gen 6) sebagai virtual server Xen. Sebuah server virtual ditambahkan sebagai load balancing yang bertugas untuk menyeimbangkan jumlah beban pada virtualisasi server VMware dan 
Xen. Desain dan skenario penelitian ditunjukkan pada Gambar 1, dan dapat dijelaskan sebagai berikut.

1. Terdapat dua server fisik digunakan untuk pengujian. Server fisik pertama digunakan untuk virtualisasi VMware dengan IP 172.16.121.79 yang terdiri dari satu mesin virtual web server dengan IP 172.16.121.78. Server fisik kedua digunakan untuk virtualisasi server Xen dengan IP 172.16.121.14 yang terdiri dari satu mesin virtual web sever dengan IP 172.16.121.18

2. Satu mesin virtual untuk load balancing digunakan dari sebuah server fisik yang berbeda. Load balancing menggunakan HAProxy dengan IP lokal 172.16.121.20 dan IP publik 103.29.196.177. Koneksi

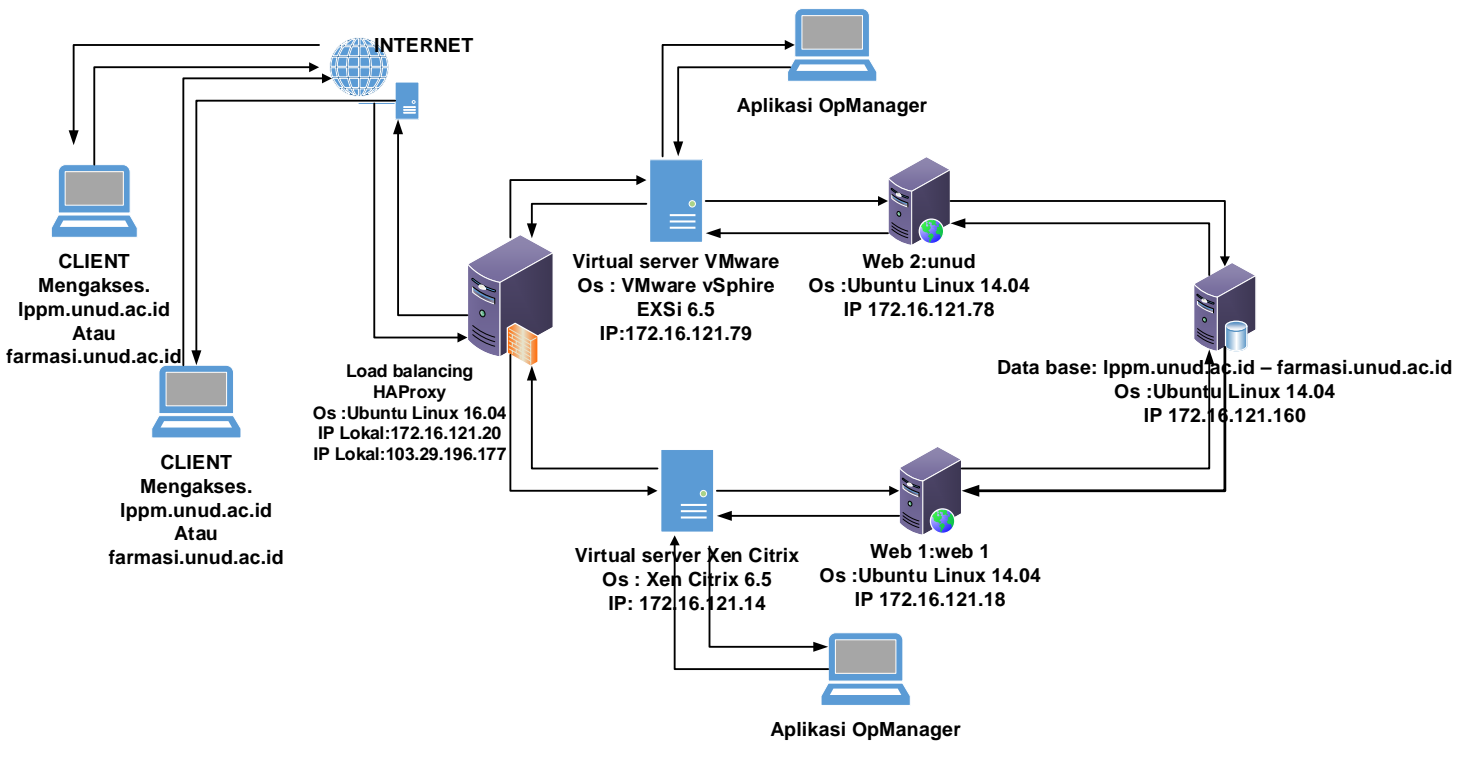

Gambar 1. Desain Dan Skenario Penelitian

Internet untuk bisa terhubung antara satu server virtual ke satu server virtual lain, satu mesin virtual ke mesin virtual lain, dari client ke server virtual dan juga

ke mesin virtual dan dari client untuk dapat mengakses aplikasi web dari masing-masing web server.

3. Untuk mendapatkan penggunaan cpu, memori dan kecepatan akses data pada saat virtualisasi VMware dan Xen menangani beban berupa aplikasi website digunakan aplikasi OpManager [10] yang dihubungkan ke masingmasing virtualisasi server VMware dan Xen dengan melakukan konfigurasi IP address dari masing-masing virtualisasi server.

4. Sehingga saat client melakukan akses internet untuk dapat terhubung ke aplikasi website Ippm.unud.ac.id dan farmasi.unud.ac.id yang terdapat di web server terlebih dulu permintaan dari client akan diproses dan diteruskan oleh load balancing ke web server dari virtualisasi server VMware dan Xen. Load balancing server bertugas untuk mencatat beban masing-masing server yang ada di belakangnya. Apabila beban lebih tinggi terdapat pada web server pertama, maka permintaan traffic berikutnya akan diberikan ke web server kedua, begitu sebaliknya. Dengan demikian load balancing server akan selalu menjaga kedua web server tersebut untuk mendapatkan beban yang sama.

\subsection{HAProxy}

HAProxy [5] adalah sebuah aplikasi

opensource berbasis Linux yang berfungsi sebagai load balancing trafik jaringan. Load balancing [6] [7] adalah teknik untuk mendistribusikan beban trafik pada dua atau lebih jalur koneksi secara seimbang agar trafik dan beban server dapat berjalan secara optimal. 
Untuk membangun HAProxy dan mengonfigurasi load balancing sehingga terhubung dengan kedua mesin virtual web server, maka dalam penelitian ini ada beberapa hal yang sudah disiapkan, yaitu:

* Sebuah mesin virtual yang telah terinstall OS (operating System) Ubuntu 14.04.

* IP address lokal 172.16.121.20 untuk haproxy

* IP address publik 103.29.196.177 untuk haproxy

* Dua mesin virtual sebagai web server back end dengan alamat IP 172.16.121.18 dan 172.16.121.78 yang berada dalam teknik load balancing. Metode load balancing yang digunakan adalah metode roundrobin dengan tujuan agar kedua web server mendapatkan jumlah beban yang seimbang.

HAProxy terinstal di mesin virtual sebagai load balancing pada OS Ubuntu 14.04, diinstall dengan cara menuliskan apt-get install haproxy. Service haproxy diaktifkan dengan mengganti atau menambahkan perintah ENABLED=1 pada file /etc/default/haproxy [5]. Konfigurasi metode load balancing dan konektivitas dengan server-server pemberi layanan dilakukan pada file /etc/haproxy/haproxy.cfg [5].

\subsection{VMware vSphere ESXi}

Gambar 2 merupakan antarmuka VMware Vsphere ESXi [8] yang sudah terinstall di server fisik HP Proliant DL 380 G7 sehingga virtual server Vmware sudah siap untuk dijalankan. Dari Gambar 2 dapat dilihat juga bahwa terdapat dua mesin virtual yang aktif dengan nama mesin virtual database dan mesin virtual web vmware.

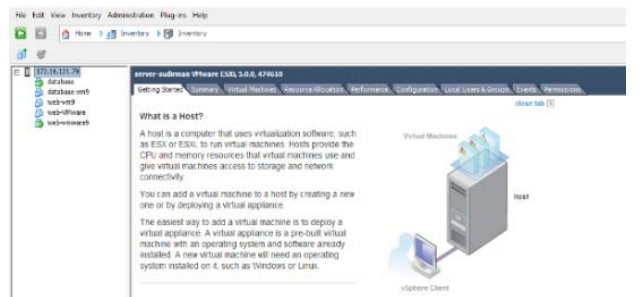

Gambar 2 VMware vSphere ESXi di Server Fisik DL 380 G7

\subsection{Server Xen}

Gambar 3 merupakan antarmuka aplikasi yang menunjukkan Xen [9] sudah terinstall di server fisik HP Proliant DL 180 G6 sehingga virtual server Xen sudah siap untuk dijalankan. Dari Gambar 3 dapat dilihat terdapat dua mesin virtual yang aktif dengan nama mesin virtual databasexencitrix dan mesin virtual web-xencitrix1.

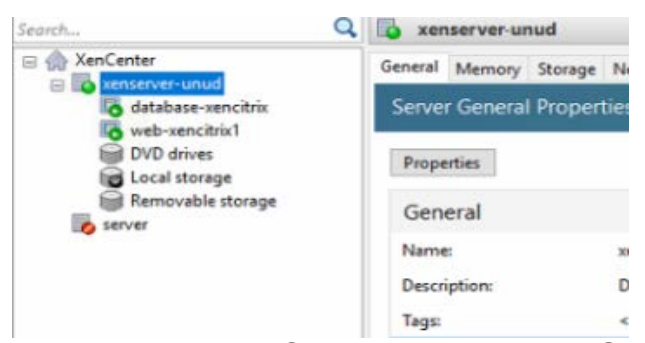

Gambar 3 Xen Di Server Fisik DL 180 G6 3.5 OpManager

OpManager, Gambar 4, adalah aplikasi yang digunakan untuk mengamati performance virtual server VMware dan virtual server XenServer. OpManager [10] adalah perangkat lunak yang digunakan untuk memantau jaringan dan mengetahui kondisi perangkat keras yang terkoneksi dalam satu jaringan berbasis IP dan SNMP.

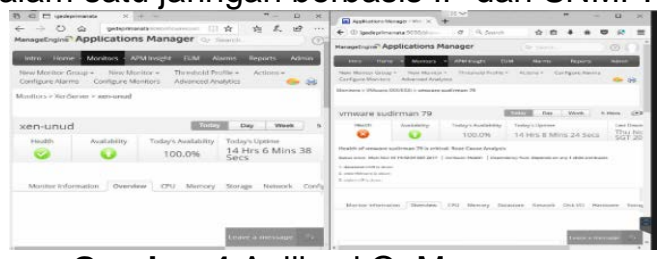

Gambar 4 Aplikasi OpManager

\section{HASIL DAN PEMBAHSAN}

\subsection{Hasil}

Sistem virtualisasi server VMware dan virtualisasi server Xen masing-masing terdiri dari satu mesin virtual dengan fungsi sebagai mesin virtual web server. Masingmasing dari virtualisasi server VMware dan virtualisasi server Xen menangani aplikasi web Ippm.unud.ac.id dan farmasi.unud.ac.id. Kedua mesin web server ini dihubungkan ke HAProxy load balancing dengan tujuan pada saat client mengakses aplikasi web Ippm.unud.ac.id atau farmasi.unud.ac.id, permintaan client tersebut tidak langsung diteruskan ke web server, melainkan permintaan client difilter terlebih dahulu di HAProxy load balancing. Selanjutnya, permintaan ini diteruskan kembali ke web server sesuai dengan algoritma round robin [6] [7] yang digunakan di load balancing. Dengan demikian jumlah permintaan dan beban 
yang ditangani dari kedua web server dari virtualisasi server VMware dan Xen tersebut sama. Dengan beban yang sama ini maka performance berupa penggunaan CPU, memori, dan kecepatan akses data kedua virtual server dapat dibandingkan. Untuk memastikan beban di kedua web server VMware dan web server Xen sama dapat dilihat melalui statistic report haproxy setelah login dari http://haproxy.unud.ac.id/haproxy_stats melalui browser yang ditunjukkan pada Gambar 5.

\subsection{Pembahasan}

Untuk mendapatkan hasil dan data dari performance penggunaan CPU, memori dan kecepatan akses data dari virtualisasi server VMware dan virtualisasi server Xen diperoleh dengan melakukan 7 hari pengamatan untuk perbandingan pada saat menangani satu website dan 10 hari pengamatan untuk perbadingan pada saat menangani dua website. Seluruh pengamatan dilakukan selama 24 jam dalam sehari terhadap jumlah permintaan client yang mengakses aplikasi web

\section{Statistics Report for pid 1440

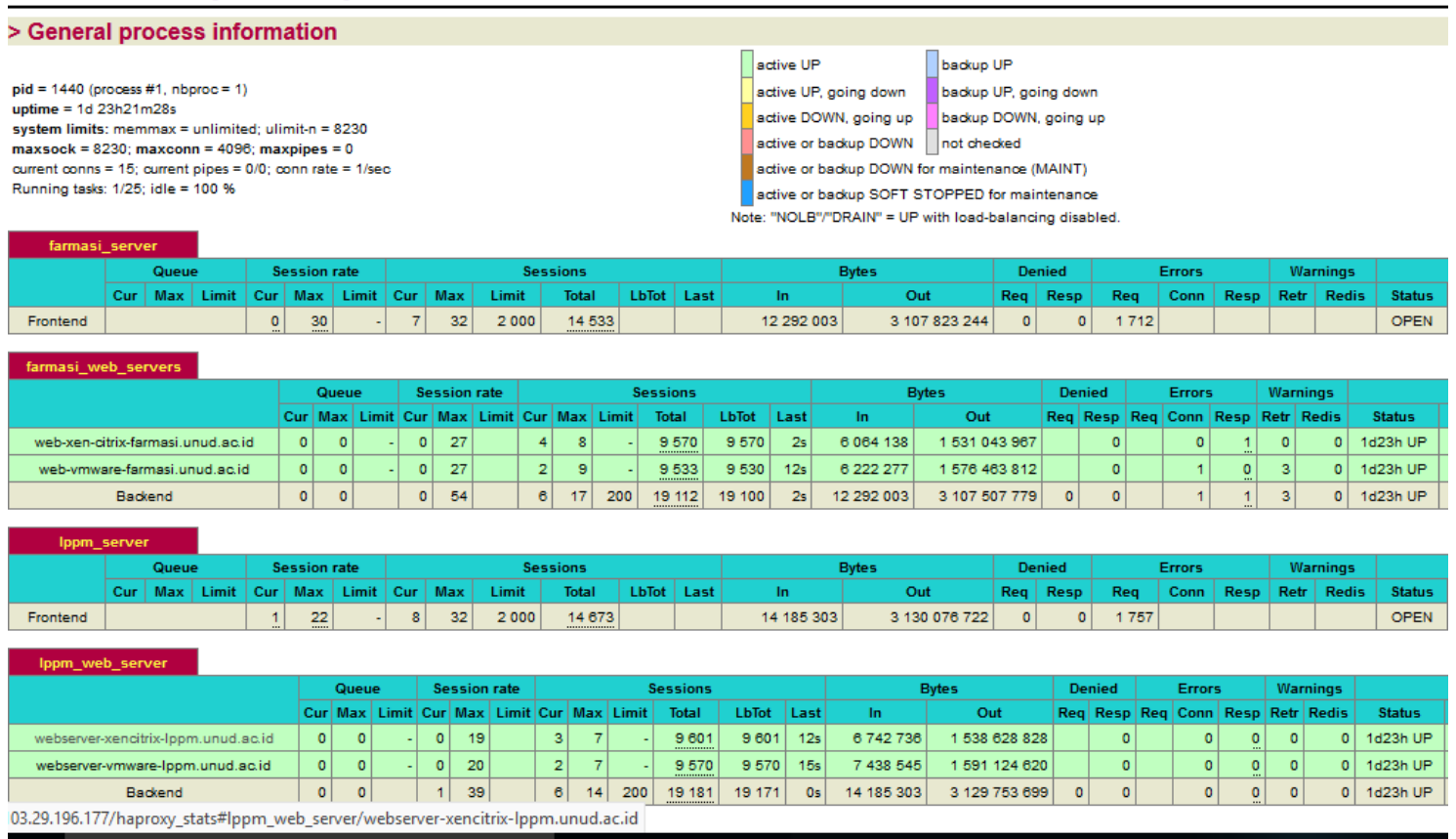

Gambar 5 Tampilan Menu Statistic Report Haproxy

Ippm.unud.ac.id dan farmasi.unud.ac.id. Pengamatan dilakukan dengan menggunakan aplikasi OpManager yang diaktifkan di masing-masing virtualisasi server dengan mengkonesikan IP address dari masing-masing virtualisasi server VMware dan Xen. 


\subsubsection{Perbandingan pada Saat Menangani Satu Website}

Ippm (Lembaga Penelitian dan Pengabdian Kepada Masyarakat) merupakan salah satu website yang dimiliki oleh Universitas Udayana. Website ini merupakan website lembaga yang berperan dalam bidang penelitian dan pengabdian masyarakat, berisikan hal-hal yang terkait dengan penelitian dan pengabdian masyarakat di lingkungan Universitas Udayana. Pengunjung website ini selalu ada setiap harinya, untuk itu website Ippm.unud.ac.id digunakan sebagai aplikasi beban dari masing-masing virtualisasi server VMware dan Xen sekaligus sebagai beban yang diamati pada saat virtualisasi server menangani satu website.

\subsubsection{Resource VMware dan Xen Pada Saat Menangani Satu Website}

Pada Tabel 1 dan Gambar 6 terlihat persentase penggunaan CPU di virtualisasi server VMware dan virtualisasi server Xen. Nilai rata-rata penggunaan CPU selama 7 (tujuh) hari untuk virtualisasi server VMware adalah $0 \%$, sedangkan pada virtualisasi server Xen adalah $1,46 \%$.

Tabel 1 Perbandingan Nilai Rata-Rata Penggunaan CPU Virtualisasi VMware Dan

\begin{tabular}{|c|c|c|c|}
\hline \multicolumn{4}{|c|}{ Xen } \\
\hline NO & HARI & $\begin{array}{c}\text { VMware } \\
\text { CPU } \\
\text { USAGE \% }\end{array}$ & $\begin{array}{c}\text { XEN CPU } \\
\text { USAGE \% }\end{array}$ \\
\hline 1 & Senin & 0 & 1,44 \\
\hline 2 & Selasa & 0 & 1,46 \\
\hline 3 & Rabu & 0 & 1,48 \\
\hline 4 & kamis & 0 & 1,64 \\
\hline 5 & Jumat & 0 & 1,37 \\
\hline 6 & Sabtu & 0 & 1,42 \\
\hline 7 & Minggu & 0 & 1,41 \\
\hline
\end{tabular}

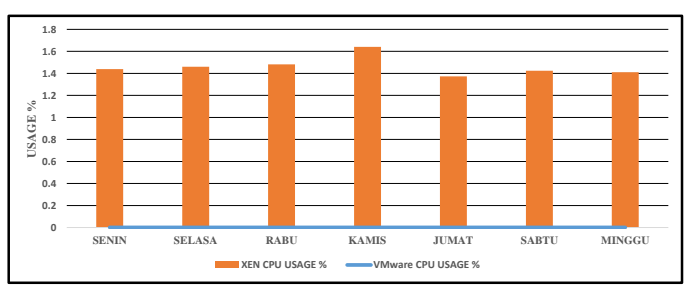

Gambar 6 Perbandingan Nilai Rata-Rata Penggunaan CPU Virtualisasi VMware Dan Xen
Tabel 2 dan Gambar 7 menunjukkan persentase penggunaan memori di virtualisasi server VMware dan virtualisasi server Xen. Nilai rata-rata penggunaan memori selama 7 (tujuh) hari untuk virtualisasi server VMware adalah 81,06\%, sedangkan pada virtualisasi server Xen adalah $51,95 \%$.

Tabel 2 Perbandingan Nilai Rata-Rata Penggunaan Memori Virtualisasi VMware Dan Xen

\begin{tabular}{|c|c|c|c|}
\hline NO & HARI & $\begin{array}{c}\text { VMware } \\
\text { MEMORI } \\
\text { USAGE \% }\end{array}$ & $\begin{array}{c}\text { XEN } \\
\text { MEMORI } \\
\text { USAGE \% }\end{array}$ \\
\hline 1 & Senin & 82,13 & 51,95 \\
\hline 2 & Selasa & 80 & 51,95 \\
\hline 3 & Rabu & 80,05 & 51,95 \\
\hline 4 & kamis & 80,15 & 51,95 \\
\hline 5 & Jumat & 81,01 & 51,94 \\
\hline 6 & Sabtu & 82,04 & 51,95 \\
\hline 7 & Minggu & 82,03 & 51,95 \\
\hline
\end{tabular}

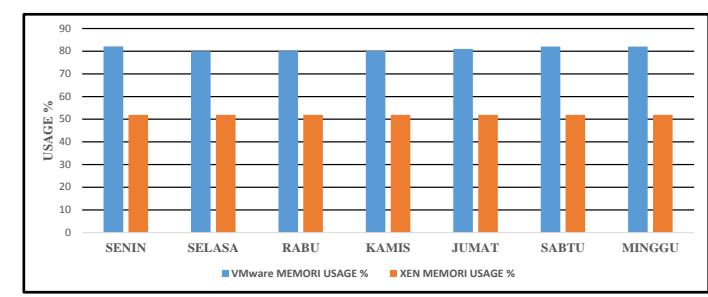

Gambar 7 Perbandingan Nilai Rata-Rata Penggunaan Memori Virtualisasi VMware Dan Xen

Statistik kecepatan akses data yang ditunjukkan dalam Tabel 3 dan Gambar 8 merupakan data transmit dan data receive pada virtualisasi server VMware dan virtualisasi server Xen. Nilai rata-rata kecepatan akses data selama 7 (tujuh) hari untuk virtualisasi server VMware adalah 30,38 Kbps, sedangkan pada virtualisasi server Xen adalah 19.382,15 Kbps.

Tabel 3 Perbandingan Nilai Rata-Rata Kecepatan Akses Data Virtualisasi VMware Dan Xen

\begin{tabular}{|c|c|c|c|}
\hline NO & HARI & $\begin{array}{c}\text { VMware } \\
\text { DATA } \\
\text { USAGE } \\
\text { Kbps }\end{array}$ & $\begin{array}{c}\text { XEN DATA } \\
\text { USAGE } \\
\text { Kbps }\end{array}$ \\
\hline 1 & Senin & 26,11 & $22.579,59$ \\
\hline 2 & Selasa & 31,86 & $33.532,29$ \\
\hline 3 & Rabu & 35,51 & $50.37,58$ \\
\hline 4 & kamis & 33,63 & $24.373,65$ \\
\hline
\end{tabular}




\begin{tabular}{|c|c|c|c|}
\hline 5 & Jumat & 29,86 & $15.006,96$ \\
\hline 6 & Sabtu & 26,77 & $17.547,64$ \\
\hline 7 & Minggu & 28,91 & $17.597,32$ \\
\hline
\end{tabular}

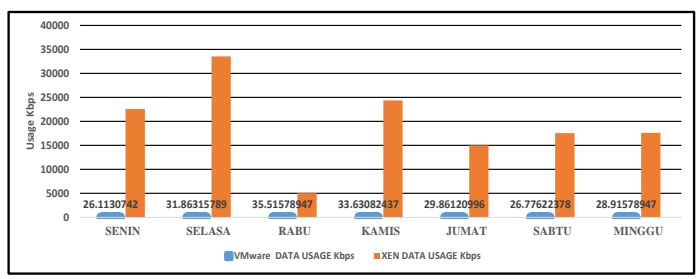

Gambar 8 Perbandingan Nilai Rata-Rata Kecepatan Akses Data Virtualisasi VMware Dan Xen

\subsubsection{Perbandingan pada Saat Menangani Dua Website}

Website Ippm.unud.ac.id dan farmasi.unud.ac.id merupakan website yang digunakan pada saat virtualisasi server VMware dan Xen menangani dua website dari kedua website tersebut yang merupakan website yang dimiliki oleh Universitas Udayana yang setiap harinya selalu ada pengunjung yang mengakses kedua website tersebut. untuk itu website Ippm.unud.ac.id dan farmasi.unud.ac.id digunakan sebagai aplikasi beban dari masing-masing virtualisasi server VMware dan Xen sekaligus sebagai beban yang diamati pada saat virtualisasi server menangani dua website.

\subsubsection{Resource VMware Dan Xen Pada Saat Menangani Dua Website}

Pada Tabel 4 dan Gambar 9 terlihat persentase penggunaan CPU di virtualisasi server VMware dan virtualisasi server Xen. Nilai rata-rata penggunaan CPU selama 10 (sepuluh) hari untuk virtualisasi server VMware adalah 0,00250\%, sedangkan pada virtualisasi server Xen adalah 1,58\%.

Tabel 4 Perbandingan Nilai Rata-Rata Penggunaan CPU Virtualisasi VMware Dan Xen

\begin{tabular}{|c|c|c|c|}
\hline NO & HARI & $\begin{array}{c}\text { VMware } \\
\text { CPU } \\
\text { USAGE } \%\end{array}$ & $\begin{array}{c}\text { Xen CPU } \\
\text { USAGE \% }\end{array}$ \\
\hline 1 & Sabtu & 0 & 1,48 \\
\hline 2 & Minggu & 0,00352 & 1,65 \\
\hline 3 & Senin & 0,00387 & 1,58 \\
\hline 4 & Selasa & 0,00706 & 1,758 \\
\hline 5 & Rabu & 0 & 1,74 \\
\hline
\end{tabular}

\begin{tabular}{|c|c|c|c|}
\hline 6 & Kamis & 0,00358 & 1,49 \\
\hline 7 & Jumat & 0,00350 & 1,44 \\
\hline 8 & Sabtu & 0 & 1,59 \\
\hline 9 & Minggu & 0,00349 & 1,54 \\
\hline 10 & Senin & 0 & 1,51 \\
\hline
\end{tabular}

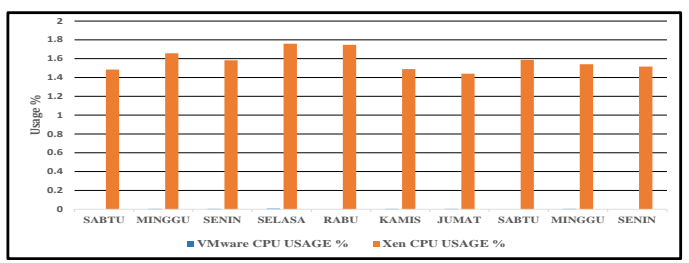

Gambar 9 Perbandingan Nilai Rata-Rata Penggunaan CPU Virtualisasi VMware Dan Xen

Pada Tabel 5 dan Gambar 10 terlihat persentase penggunaan memori di virtualisasi server VMware dan virtualisasi server Xen. Nilai rata-rata penggunaan memori selama selama 10 (sepuluh) hari untuk virtualisasi server VMware adalah $86,78 \%$, sedangkan pada virtualisasi server Xen adalah 51,95\%.

Tabel 5 Perbandingan Nilai Rata-Rata Penggunaan Memori Virtualisasi VMware

\begin{tabular}{|c|c|c|c|}
\hline \multicolumn{3}{|c|}{ Dan Xen } \\
\hline NO & HARI & $\begin{array}{c}\text { VMware } \\
\text { Memori } \\
\text { USAGE \% }\end{array}$ & $\begin{array}{c}\text { Xen } \\
\text { Memori } \\
\text { USAGE } \\
\%\end{array}$ \\
\hline 1 & Sabtu & 87,08 & 51,95 \\
\hline 2 & Minggu & 87,16 & 51,95 \\
\hline 3 & Senin & 87,09 & 51,95 \\
\hline 4 & Selasa & 87,18 & 51,95 \\
\hline 5 & Rabu & 87,59 & 51,95 \\
\hline 6 & Kamis & 86,50 & 51,95 \\
\hline 7 & Jumat & 86,03 & 51,95 \\
\hline $\mathbf{8}$ & Sabtu & 87,08 & 51,95 \\
\hline $\mathbf{9}$ & Minggu & 86,03 & 51,95 \\
\hline $\mathbf{1 0}$ & Senin & 86,07 & 51,95 \\
\hline
\end{tabular}

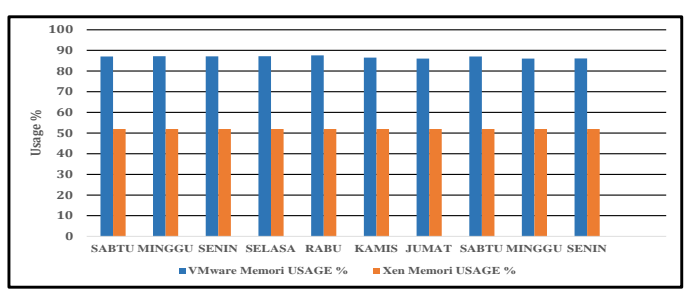

Gambar 10 Perbandingan Nilai Rata-Rata 
Penggunaan Memori Virtualisasi VMware Dan Xen

Statistik kecepatan data yang ditunjukkan dalam Tabel 6 dan Gambar 11 merupakan data transmit dan data receive pada virtualisasi server VMware dan virtualisasi server Xen. Nilai rata-rata kecepatan data selama 10 (sepuluh) hari untuk virtualisasi server VMware adalah 46,70 Kbps, sedangkan pada virtualisasi server Xen adalah 42.179,18 Kbps.

Tabel 6 Perbandingan Nilai Rata-Rata Kecepatan Akses Data Virtualisasi VMware Dan Xen

\begin{tabular}{|c|c|c|c|}
\hline NO & HARI & $\begin{array}{c}\text { VMware } \\
\text { Data USAGE } \\
\text { Kbps }\end{array}$ & $\begin{array}{c}\text { Xen Data } \\
\text { USAGE } \\
\text { Kbps }\end{array}$ \\
\hline 1 & Sabtu & 51,66 & $52.050,75$ \\
\hline 2 & Minggu & 38,98 & $28.522,86$ \\
\hline 3 & Senin & 49,05 & $41.016,85$ \\
\hline 4 & Selasa & 51,34 & $42.202,59$ \\
\hline 5 & Rabu & 64,06 & $81.696,89$ \\
\hline 6 & Kamis & 42,49 & $32.962,32$ \\
\hline 7 & Jumat & 37,76 & $31.163,93$ \\
\hline 8 & Sabtu & 51,66 & $5.2050,74$ \\
\hline 9 & Minggu & 38,46 & $22.797,51$ \\
\hline 10 & Senin & 41,52 & $37.327,30$ \\
\hline
\end{tabular}

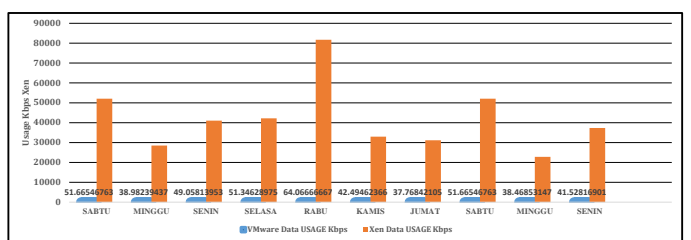

Gambar 11 Perbandingan Nilai Rata-Rata Kecepatan Akses Data VirtualisasiVMware

5. KESIMPULAN

Dan Xen

Teknik virtualisasi server baik VMware atau Xen dapat membantu penggunaan bersama resource server untuk fungsi server dan aplikasi yang berbeda sehingga menghemat biaya, ruang, dan waktu pengelolaan server. Dari penelitian ini diperoleh hasil bahwa penggunaan CPU di VMware lebih rendah dibandingkan dengan Xen dengan nilai $1,57 \%$ pada saat menangani satu website dan 1,58\% lebih rendah pada saat menangani dua website. Sedangkan Xen lebih hemat memori sebesar 29,11\% dan 34,83\% untuk menangani satu dan dua website jika dibandingkan dengan VMware. Jika ditinjau dari kecepatan akses data, maka Xen lebih cepat dibandingkan dengan VMware, yaitu sekitar 42.132,47 Kbps.

Perbandingan VMware dan Xen ini dilakukan pada metode load balancing HAProxy dengan algoritma round robin dengan asumsi bahwa beban yang diberikan pada kedua server beck end adalah sama. Agar hasil ini lebih valid, perlu dibandingkan dengan metode lain yang dapat membandingkan secara sama untuk masing-masing metode virtualisasi ini.

Karakteristik masing-masing virtualisasi yang berbeda ini dapat digunakan sebagai pilihan pada karakteristik aplikasi yang berbeda. Untuk itu, penelitian ini dapat dikembangkan ke arah klasifikasi aplikasi dalam pemilihan virtualiasi yang lebih cocok.

\section{DAFTAR PUSTAKA}

[1] Sanjaya, I., and N. I. M. E. A. D. Wirastuti. "Analisis Skalabilitas Server Virtualisasi pada Akademi Manajemen Informatika dan Komputer New Media." Majalah IImiah Teknologi Elektro 13, no. 1, 2014.

[2] Swati Pawar, Sarvesh Singh, Performance Comparison of VMware and Xen Hypervisor on Guest OS, International Journal of Inovatif IImu Komputer \& Teknik.2015;2(3):56-60.

[3] Hien Nguyen Van, Fr'ed'eric Dang Tran, Jean-Marc Menaud, Autonomic Virtual resource Management for Service Hosting Platforms, HAL archivees-ouvertes. 2010;5(10):1-5.

[4]. Rio Rasian, Petrus Mursanto, Perbandingan Kinerja Pendekatan Virtualisasi, Journal of Information Systems. 2009;5:90-91.

[5] Ari Budi Noviyanto, Erna Kumalasari N, Amir Hamzah, Perancangan Dan Implementasi Load Balancing Reverse Proxy Menggunakan Haproxy pada Aplikasi Web,Jurnal JARKOM.2015;3(1):21-31

[6] Dipak Wajgi, Dr.Nileshingh V.Thakur, Load Balancing Based Approach To Improve Lifetime Of Wireless Sensor Network, International Journal Of wireless \& Mobile Networks (IJWMN).2012;4(4):155-165

[7]. Dwi Septian Wardana Putra, Agus Eko Minarno, Zamah sari, Perancangan Dan Implementasi Load Balancing Dan 
Faillover Clustering Pada linux Virtual

Server (LVS) Untuk High Avabailty.Jurnal JARKOM.2013;1(1):15.

[8] Sogand Shirinbab, Lars Lundberg, Dragosllie, Performance Comparison of KVM, VMware and XenServer Using Large Telecommunication Applications,

CLOUD COMPUTING 2014: The Fifth International Conference on Cloud Computing, GRIDs, and Virtualization. 2014.

[9] Mr Vikas Malik, Prof. CR Barde, Survai Arsitektur Hypervisor Leading dan teknik Live Migration, International Jurnal of IImu Komputer dan teknologi Informasi.2014;3:65-72

[10] Bambang Suhartono, Sistem Monitoring Dan Avaiilability Server Serta Perangkat Jaringan Dengan Menggunakan Aplikasi OpManager Dan Gammu, Jurnal IT.2012;6(1):1-13 